\title{
Pirâmide alimentar para crianças de 2 a 3 anos
}

\author{
Food guide pyramid for young children 2 to 3 years old
}

Sonia Tucunduva PHILIPPI ${ }^{1}$

Ana Teresa Rodrigues CRUZ²

Ana Carolina Almada $\mathrm{COLUCCl}^{3}$

\section{RE S U M O}

Com a finalidade de promover orientação nutricional e hábitos alimentares saudáveis para crianças de 2 a 3 anos de idade, fez-se a adaptação da Pirâmide Alimentar. A pirâmide foi baseada em dieta padrão (1300kcal) com seis refeições, calculada de acordo com as recomendações para a idade. As porções e os equivalentes foram estabelecidos de acordo com o total de energia de cada alimento utilizando-se o software Virtual Nutri. Foi avaliada a distribuição percentual dos macronutrientes em relação ao valor energético total, obtendo-se $15 \%$ para proteínas, 59\% para carboidratos e $26 \%$ para lipídios. Foram calculados ainda os valores para ferro total e ferro biodisponível. Os alimentos estão organizados em oito grupos: arroz, pão, massa, batata, mandioca (5 porções), verduras e legumes (3 porções), frutas (3 porções), carnes e ovos (2 porções), leite, queijo e iogurte (3 porções), feijões (1 porção), óleos e gorduras (1 porção) e açúcares e doces (1 porção). A pirâmide alimentar apresenta-se como um instrumento importante para orientação nutricional, servindo como guia para o planejamento de uma alimentação saudável para crianças de 2 a 3 anos de idade.

Termo de indexação: criança, dieta, hábitos alimentares, pirâmide alimentar.

\section{A B S T R A C T}

The objective of this paper was to develop a Food Guide Pyramid for young children 2 to 3 years old, aiming to promote nutritional orientation and healthful food habits. The Food Guide Pyramid was based on a standard diet (1300kcal) with six meals, which was calculated in accordance with the recommendations for this age group. The portions and food equivalents were established according to the total amount of energy of each food, using the "Virtual Nutri" software. The distribution of macronutrients in relation to the total caloric value was evaluated and the following results were found: 15\% for proteins, 59\% for carbohydrates

\footnotetext{
1 Departamento de Nutrição, Faculdade de Saúde Pública, Universidade de São Paulo. Av. Dr. Arnaldo, 715, $2^{\circ}$ andar, 01246-904, São Paulo, SP, Brasil. Correspondência para/Correspondence to: S.T. PHILIPPI.

2 Mestre em Nutrição Humana Aplicada, do Curso Interunidades, Universidade de São Paulo.

${ }^{3}$ Mestre, área de concentração Nutrição, Faculdade de Saúde Pública, Universidade de São Paulo.
} 
and $26 \%$ for lipids. The values of total iron and bioavailable iron were also calculated. The foods are distributed in eight groups: rice, bread, pasta, potato, cassava (5 portions), vegetables (3 portions), fruits (3 portions), meat and eggs (2 portions), milk, cheese and yogurt (3 portions), beans (1 portion), oils and fats (1 portion) and sugar and sweets (1 portion). The Food Guide Pyramid is an important instrument for nutritional orientation, serving as a guide to establish a healthful diet for children 2 to 3 years old.

Index terms: child, diet, food habits, food guide pyramid.

\section{N T R O D U Ç Ã O}

Nos primeiros anos de vida, é essencial para o crescimento e desenvolvimento da criança uma alimentação qualitativa e quantitativamente adequada, pois ela proporciona ao organismo a energia e os nutrientes necessários para o bom desempenho de suas funções e para a manutenção de um bom estado de saúde ${ }^{1}$. As práticas alimentares são adquiridas durante toda a vida, destacando-se os primeiros anos como um período muito importante para o estabelecimento de hábitos alimentares que promovam a saúde do indivíduo.

Para as crianças entre 2 e 3 anos de idade, a alimentação deve ser capaz de suprir as demandas de macro e micronutrientes ${ }^{2}$. A necessidade de maior cuidado em relação à alimentação deste grupo decorre principalmente do fato de nessa faixa etária ocorrer a incorporação de novos hábitos alimentares, implicando o conhecimento de novos sabores, texturas e cores, experiências sensoriais que influenciarão diretamente o padrão alimentar a ser adotado pelo infante 3 . Durante este período, a alimentação da criança pode ser a mesma da família, com algumas adaptações em relação à forma de preparo e apresentação dos alimentos de acordo com a idade 3,4 .

As crianças com 2 e 3 anos de idade apresentam maior estabilidade no crescimento, devido à diminuição da velocidade de ganho de peso e estatura, o que condiciona diminuição do apetite. Por isso, as demandas de energia e de proteínas por quilo de peso diminuem em comparação com as necessidades durante o primeiro ano de vida².
Nesta fase, o infante está desenvolvendo sua coordenação motora, com destaque à aquisição da capacidade de se alimentar sozinho. O estabelecimento de horários regulares para as refeições e a seleção de utensílios (copos, pratos e talheres) adequados para cada idade apresentam-se como condição importante para a aceitação e experimentação dos alimentos. Os lanches, como refeições intermediárias, devem ser saudáveis, pois nesta idade os hábitos alimentares estão em formação ${ }^{2,4}$.

O apetite da criança de 2 a 3 anos é irregular e pode variar de um dia para o outro. Assim, em um dia ela pode aceitar determinado alimento e no outro recusá-lo, atitude que pode originar ansiedade na família e nas pessoas responsáveis pelo seu cuidado ${ }^{5}$.

Recomenda-se fazer a introdução de novos alimentos e preparações de forma gradual, respeitando-se os interesses da criança e auxiliando no aprendizado do consumo de uma dieta equilibrada. A criança, ao experimentar e aceitar o alimento, apresenta uma grande chance de aprová-lo e incluí-lo em seus hábitos alimentares ${ }^{4,6}$.

Conduzir de forma apropriada a alimentação da criança requer cuidados relacionados aos aspectos sensoriais (apresentação visual, cores, formatos atrativos), à forma de preparo dos alimentos (temperos suaves, preparações simples e alimentos básicos), às porções adequadas à capacidade gástrica restrita e ao ambiente onde serão realizadas as refeições, que são fatores a serem considerados, visando a satisfação de necessidades nutricionais, 
emocionais e sociais, para a promoção de uma qualidade de vida saudável ${ }^{4,6}$.

A alimentação, envolvida por emoções e sensações, apresenta-se como um ato de convívio social, no qual os alimentos são fortes representações psicológicas criadas em cada indivíduo, a partir do seu relacionamento único e intransferível com os produtos a serem ingeridos por ele. Essas experiências são conduzidas desde o nascimento, com o aleitamento materno e, posteriormente, com ações e reações diante dos alimentos, e influenciadas constantemente pela forma como eles são oferecidos.

A criança deve consumir a quantidade de alimento necessária para alcançar seu potencial genético de crescimento. O tamanho corporal a ser alcançado na vida adulta não é de primordial importância; entretanto, o atraso no crescimento, devido às circunstâncias nutricionais e ambientais, está associado com maiores taxas de morbidade e mortalidade, com deficiências no aprendizado e com menor capacidade física e intelectual na vida adulta ${ }^{6}$.

As fases da vida pré-escolar e escolar e da adolescência são excelentes momentos para uma orientação nutricional ativa e participativa, portanto, a alimentação deve ser saudável e adequada a cada uma destas fases, respeitando-se as características individuais $5^{6,7}$.

Com a finalidade de orientar a população, são estabelecidos os guias alimentares, os quais devem ser entendidos como instrumentos educativos, para orientação nutricional e alimentar, que, baseados nas recomendações nutricionais, nos hábitos e nos comportamentos alimentares, informam os indivíduos sobre a seleção, a forma e a quantidade de alimentos a ser consumida. Diversos países têm apresentado guias de acordo com seus hábitos alimentares, disponibilidade de alimentos e necessidades nutricionais dos diferentes grupos populacionais8.

Os guias alimentares são expressos na forma de ícones (pirâmides, arco-íris, e outros), com os grupos de alimentos representados por figuras, em diferentes níveis, e com o estabelecimento das porções para o consumo. As medidas caseiras, os pesos em gramas e os equivalentes em energia dos diferentes alimentos consumidos em refeições representam as orientações básicas para uma alimentação saudável. Peña \& Molina (1998) também descrevem o Guia Alimentar como "instrumento educativo que adapta os conhecimentos científicos sobre requerimentos nutricionais e composição de alimentos em mensagens práticas que facilitam a diferentes pessoas a seleção e o consumo de alimentos saudáveis".

Considerando a complexidade dos fatores envolvidos na alimentação das crianças de 2 a 3 anos e as dificuldades na oferta de uma dieta adequada, deve ser enfatizado o papel fundamental dos pais, educadores e profissionais da área da saúde na formação de bons hábitos alimentares e na construção de uma atitude madura da criança em relação aos alimentos. Assim, surgiu a necessidade de desenvolver um instrumento para orientação nutricional, baseado na proposta da Pirâmide Alimentar, que fosse adaptado às crianças entre 2 e 3 anos de idade.

\section{CASUÍSTICA MÉTODOS}

A partir da Pirâmide Alimentar adaptada para a população brasileira foram desenvolvidas outras pirâmides alimentares ${ }^{6,8,10-13}$. Esta pirâmide para crianças de 2 a 3 anos de idade foi baseada em dieta padrão planejada para esta faixa etária, contendo os alimentos mais comumente consumidos.

A quantidade de dieta de $1300 \mathrm{kcal}$ foi calculada de acordo com a recomendação ${ }^{14}$ para indivíduos nessa idade, estabelecendo-se as porções em função dos grupos dos alimentos (cereais, leguminosas, hortaliças, frutas, leite, carnes e ovos, açúcares e gorduras). O tamanho das porções foi adaptado de acordo com a faixa etária, considerando-se a limitada capacidade gástrica das crianças nessa idade. 
A dieta foi elaborada com alimentos típicos e do hábito alimentar, distribuídos em seis refeições (café da manhã, lanche da manhã, almoço, lanche da tarde, jantar e lanche da noite).

O cálculo da dieta padrão foi realizado utilizando-se o software "Virtual Nutri" 15 que possui informações de alimentos in natura; de preparações com alimentos básicos da dieta, realizadas no Laboratório de Técnica Dietética da Faculdade de Saúde Pública da Universidade de São Paulo; de alimentos industrializados, cujos dados foram obtidos diretamente nos Centros de Informação ao Consumidor das empresas e através de coleta dos dados expressos nos rótulos de embalagens.
As porções foram estabelecidas por refeição, de acordo com o total de energia de cada alimento e da dieta (1300kcal), respeitando-se o número de porções de cada grupo.

Foram elaboradas tabelas de alimentos com os equivalentes (em energia) de cada nível da pirâmide, com as respectivas porções em medidas caseiras e em gramas, possibilitando as indicações para as substituições.

\section{RESULTA DOS}

Foi avaliada a distribuição percentual dos macronutrientes em relação à dieta estabelecida de $1300 \mathrm{kcal}$, obtendo-se $15 \%$ para proteínas,

Tabela 1. Dieta para criança de 2 a 3 anos (1300kcal), com respectivos alimentos, pesos (gramas), medidas caseiras, porções e grupos.

\begin{tabular}{|c|c|c|c|c|}
\hline Alimento & Peso (g) & Medida Caseira & Porção & Grupo \\
\hline \multicolumn{5}{|l|}{ Café da manhã } \\
\hline Leite tipo B & 182 & 1 xícara (chá) & 1 & Leite \\
\hline Achocolatado & 9 & $1 / 2$ colher (sopa) rasa & $1 / 2$ & Açúcares \\
\hline Biscoito Maizena ${ }^{\circledR}$ & 20 & 4 unidades & 1 & Arroz \\
\hline \multicolumn{5}{|l|}{ Lanche da manhã } \\
\hline Banana nanica & 43 & $1 / 2$ unidade & 1 & Frutas \\
\hline Aveia em flocos & 18 & $11 / 2$ colher (sopa) & 1 & Arroz \\
\hline \multicolumn{5}{|l|}{ Almoço } \\
\hline Arroz branco & 62 & 2 colheres (sopa) & 1 & Arroz \\
\hline Feijão (50\% grão / 50\% caldo) & 26 & 1 colher (sopa) & 1 & Feijões \\
\hline Espetinho de fígado & 34 & $1 / 4$ unidade & 1 & Carnes \\
\hline Batata cozida & 88 & 1 unidade & 1 & Arroz \\
\hline Cenoura cozida & 20 & 4 fatias & 1 & Verduras e Legumes \\
\hline \multicolumn{5}{|l|}{ Lanche da tarde } \\
\hline logurte com polpa de fruta & 120 & 1 pote & 1 & Leite \\
\hline \multicolumn{5}{|l|}{ Jantar } \\
\hline Macarrão cozido & 53 & 2 colheres (sopa) & 1 & Arroz \\
\hline Molho de tomate & 20 & 1 colher (sopa) & 1 & Verduras e Legumes \\
\hline Carne moída refogada & 30 & 2 colheres (sopa) & 1 & Carnes \\
\hline Vagem cozida & 22 & 1 colher (sopa) & 1 & Verduras e Legumes \\
\hline Salada de frutas & 165 & 5 colheres (sopa) & 2 & Frutas \\
\hline \multicolumn{5}{|l|}{ Lanche da noite } \\
\hline Leite tipo B & 182 & 1 xícara (chá) & 1 & Leite \\
\hline Açúcar refinado & 7 & 1/4 colher (sopa) & $1 / 2$ & Açúcares \\
\hline
\end{tabular}

Energia Total $=1247,79$ kcal. Dados obtidos do Software "Virtual Nutri".

A quantidade de óleo utilizada já está incluída nas preparações, estimada em $8 \mathrm{~g}$ de óleo/dia. 
59\% para carboidratos e 26\% para lipídios. Cabe destacar que todos os nutrientes encontram-se dentro dos intervalos preconizados: proteína - 10\% a $15 \%$, carboidrato - $50 \%$ a $60 \%$ e lipídio - $20 \%$ a $30 \%{ }^{6}$.

Os alimentos componentes da dieta (Tabela 1) foram distribuídos em seis refeições, especificando-se os pesos em gramas, as medidas caseiras, as porções e os grupos a que pertencem de acordo com os níveis da pirâmide.

Decidiu-se empregar a estrutura da pirâmide, considerando-se a experiência bem sucedida de sua utilização e indicação para orientação nutricional de indivíduos adultos, pois expressa de forma clara como escolher os alimentos que devem ser consumidos.

A pirâmide infantil foi dividida, então, em quatro níveis:

Primeiro nível: Grupo do arroz, pão, massa, batata, mandioca: constituído por cereais, tubérculos e raízes, fontes de carboidratos; contribui com a maior parte das calorias da dieta -5 porções, sendo pelo menos uma de grãos integrais.

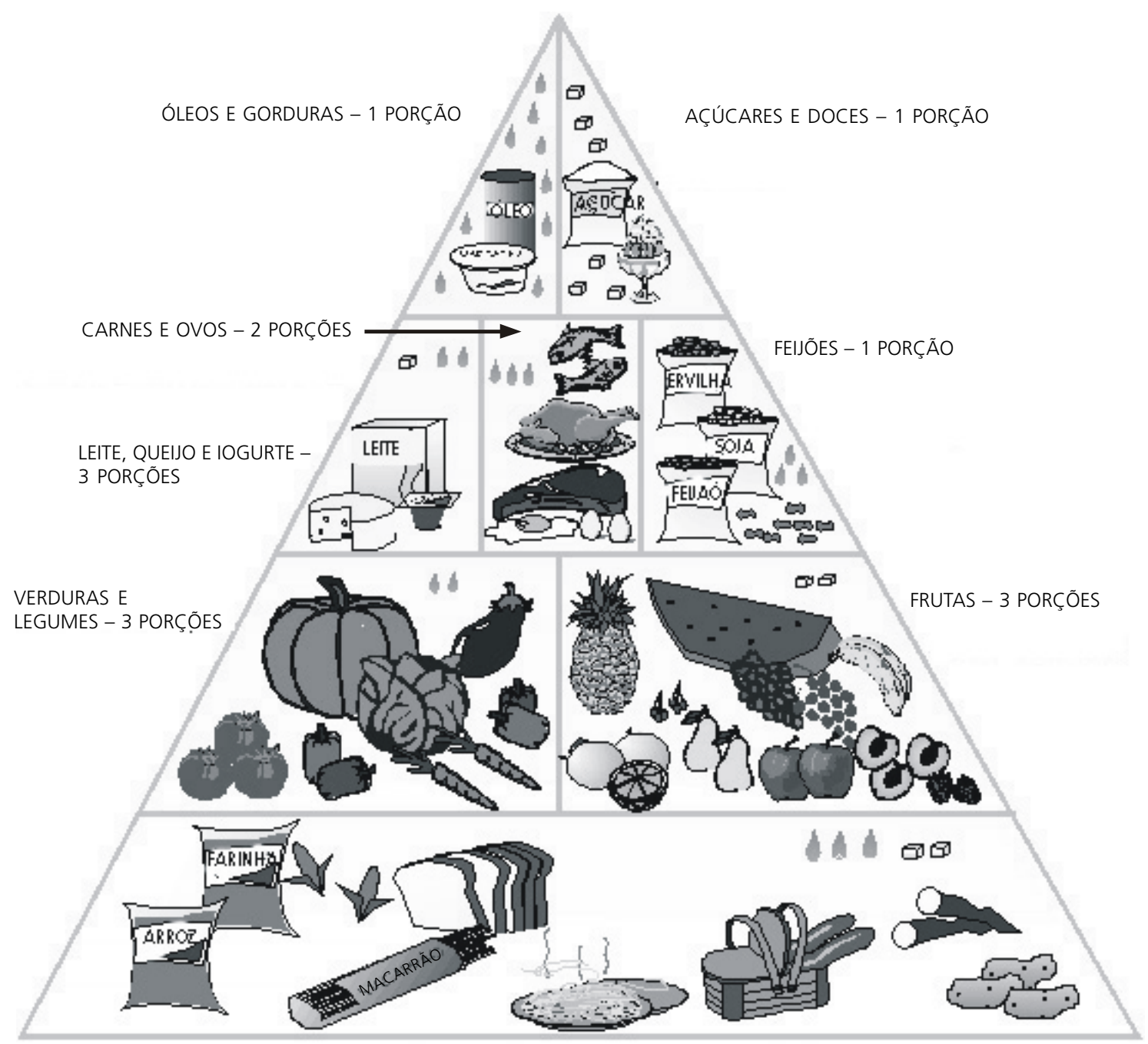

ARROZ, PÃO, MASSA, BATATA, MANDIOCA - 5 PORÇÕES

Figura 1. Pirâmide Alimentar Infantil - 2 a 3 anos de idade. 
Segundo nível: Grupo das verduras e legumes e Grupo das frutas: fontes de vitaminas e minerais - 3 porções.

Terceiro nível: Grupo do leite, queijo e iogurte: fontes de proteínas, cálcio e vitaminas - 3 porções; Grupo das carnes e ovos: alimentos fontes de proteínas, ferro e vitaminas; inclui carne bovina e suína, aves, peixes e frutos do mar, vísceras e ovos - 2 porções; Grupo dos feijões: inclui feijão, soja, ervilha, grão de bico, fava e amendoim; alimentos fontes de proteína vegetal -1 porção.

Quarto nível: Grupo dos óleos e gorduras (margarina/manteiga, óleo) e Grupo dos açúcares e doces (doces, mel e açúcares): fontes de gorduras e carboidratos, respectivamente; os alimentos destes grupos devem ser consumidos com moderação, pois se encontram no topo e em todos os outros níveis da pirâmide, estando presentes na composição e preparação dos alimentos -1 porção.

Os oito grupos foram compostos com alimentos semelhantes (Figura 1) e foi definido o número de porções diárias para cada grupo (os valores das porções estão de acordo com a dieta padrão calculada).

Com relação à distribuição das refeições, $19 \%$ do valor calórico total (VCT) diário se concentra no café da manhã, $23 \%$ no almoço e $24 \%$ no jantar. O restante se distribui entre os lanches intermediários, sendo cerca de $10 \%$ em cada um. Esta distribuição não segue aquela recomendada para adultos ${ }^{6}$, considerando-se que as calorias devem ser distribuídas mais homogeneamente durante o dia, não se concentrando apenas nas refeições principais.

Foi realizado o cálculo do ferro biodisponível da dieta apresentada $(1300 \mathrm{kcal})$, aplicando-se o modelo teórico proposto por Monsen \& Balintfy $(1982)^{16}$, onde é considerada como fator estimulante da absorção do ferro a presença de carne e vitamina $C$ nas refeições ${ }^{17}$. De acordo com os valores obtidos por refeição e o total diário (Tabela 2), a dieta proposta atinge $91,10 \%$ do valor recomendado para o ferro total $(10 \mathrm{mg})$ e $112,86 \%$ para o ferro biodisponível $(0,7 \mathrm{mg})$, para crianças de 2 a 3 anos $^{14}$.

Tabela 2. Ferro total e biodisponível da dieta de $1300 \mathrm{kcal}$ para crianças de 2 a 3 anos de idade.

\begin{tabular}{lcc}
\hline Refeição & Ferro total (mg) & Ferro biodisponível (mg) \\
\hline Café da manhã & 0,52 & 0,018 \\
Lanche da manhã & 1,22 & 0,041 \\
Almoço & 3,41 & 0,380 \\
Lanche da tarde & 0,20 & 0,006 \\
Jantar & 3,23 & 0,320 \\
Lanche da noite & 0,53 & 0,020 \\
\hline Total/dia & 9,11 & 0,790 \\
\hline
\end{tabular}

Para cada grupo da pirâmide, foram estabelecidas as porções dos alimentos equivalentes em energia, cujos valores foram obtidos no software "Virtual Nutri"15. Para a elaboração dos equivalentes, os componentes da dieta tiveram seus valores energéticos fixados em função da quantidade presente. Os oito grupos da pirâmide com os respectivos alimentos e seus equivalentes em porções (medidas caseiras e gramas) foram relacionados (Anexos 1 a 8) com o objetivo de definir produtos substitutos para os componentes de uma dieta qualitativa e quantitativamente equilibrada e especificar seus equivalentes em energia, além de facilitar o entendimento e a transmissão das orientações em termos do tamanho das porções.

Visando complementar a orientação nutricional, baseada na pirâmide alimentar infantil, foram definidas algumas recomendações básicas: escolher uma dieta variada com alimentos de todos os grupos da pirâmide; dar preferência aos vegetais como frutas, verduras e legumes; ficar atento ao modo de preparo dos alimentos, procurando facilitar a mastigação e deglutição pelas crianças e dando prioridade aos alimentos em sua forma natural e às preparações assadas, cozidas em água ou vapor e grelhadas; apresentar as preparações culinárias de maneira a atrair a atenção das crianças; ler os rótulos dos alimentos infantis industrializados para conhecer o valor nutritivo do alimento e o modo de preparo; 
introduzir novos alimentos e preparações de forma gradual e insistente, para que a criança possa aprovar e incluir em seus hábitos alimentares; utilizar açúcares, doces, sal e alimentos ricos em sódio com moderação; consumir alimentos com baixo teor de gordura, dando preferência às carnes magras; usar gorduras poliinsaturadas encontradas em óleos vegetais (girassol, milho, canola e soja).

\section{I S C U S S Ã O}

A discussão pode ser conduzida sob dois aspectos: um referente aos grupos e quantidades de alimentos propostos na dieta das crianças de 2 a 3 anos e outro sobre a presença e necessidade de guias alimentares para a população infantil.

Foi necessária a adequação do tamanho da porção ao consumo habitual, às variações com relação ao apetite, bem como à limitada capacidade gástrica das crianças de 2 a 3 anos, considerando-se que porção é a quantidade de alimento em sua forma usual de consumo, estabelecida a partir das necessidades nutricionais de cada grupo etário ${ }^{6}$. Assim, o tamanho das porções mostra-se menor quando comparado com as quantidades para adultos no tocante à maioria dos grupos de alimentos, mantendo-se inalterado apenas para o Grupo das frutas e para o Grupo do leite, queijo e iogurte.

O leite mereceu atenção especial pelo fato de ser fonte de cálcio, micronutriente importante em todas as fases da vida e essencial durante a infância para a mineralização óssea e manutenção do crescimento ósseo. Com porções diárias de leite consegue-se, em média, $800 \mathrm{mg}$ de cálcio, suficientes para cobrir as necessidades exigidas para crianças ${ }^{14}$.

Os óleos, as gorduras, os açúcares e os doces devem ter seu consumo moderado, uma vez que já existem de forma natural, de composição ou de adição, em vários alimentos e preparações. As legendas para óleos (gota) e açúcares (cubo) estão distribuídas por todos os níveis da pirâmide 5 .
É recente a discussão sobre a presença de guias alimentares nos países da América Latina e a necessidade de desenvolvê-los e implementá-los. Os estudos tiveram início a partir de 1992, com a Conferência Mundial de Nutrição em Roma ${ }^{18}$.

Em 1994, o México e a Venezuela eram os únicos países da América Latina que já possuíam guias alimentares formulados. A Costa Rica iniciou o processo no mesmo ano com um diagnóstico epidemiológico da população e posterior elaboração dos guias alimentares. Alguns países elaboraram, validaram e reproduziram seus guias alimentares, os quais estão em processo de implementação, como Chile, Costa Rica, Guatemala, Panamá e Venezuela ${ }^{18}$.

A maioria dos países mencionados desenvolveram os guias alimentares para a população adulta e saudável| ${ }^{18}$. A inexistência de guias específicos para a população infantil se deve à dificuldade nas adaptações dos conteúdos, das mensagens e das porções de alimentos expressas, com o propósito de torná-los compreensíveis e motivadores.

No Chile, Yañez et al. (2000) ${ }^{19}$, com a finalidade de facilitar o uso da Pirâmide Alimentar, validaram estes instrumentos para crianças em idade escolar. Na Argentina, no ano de 2000, foram desenvolvidos Guias Alimentares para a população adulta saudável e recomendou-se a definição de guias específicos para menores de 2 anos.

No Brasil, um esforço conjunto do Ministério da Saúde, da Organização PanAmericana da Saúde (OPAS) e de universidades produziu um guia alimentar para crianças de 6 a 24 meses, considerando o perfil epidemiológico e os hábitos alimentares desta população ${ }^{20}$.

Mesmo com poucos trabalhos publicados na área de guias alimentares infantis, é válida a discussão dos presentes resultados, com relação a grupos, tipos de alimentos e preparações, formas usuais de consumo e 
tamanho das porções. Ressalta-se que o guia descrito nesta pesquisa necessita de validação e implementação, fases enfaticamente recomendadas pelos organismos internacionais.

\section{O N CLUS Ã O}

A pirâmide alimentar desenvolvida para crianças de 2 a 3 anos de idade apresenta-se como um instrumento para orientação de pais, educadores e profissionais da área da saúde sobre a melhor forma de conduzir a alimentação infantil, servindo como guia para uma alimentação saudável.

Para a elaboração da pirâmide alimentar foram considerados fatores como a disponibilidade e a presença de alimentos que fazem parte do hábito dos brasileiros, contribuindo para o processo de adaptação da criança ao consumo alimentar da família. O tamanho das porções está adaptado às características da idade da criança, às variações do apetite e à limitada capacidade gástrica, possibilitando também fácil entendimento e aplicação.

É importante que a pirâmide alimentar seja sempre avaliada e adaptada em função dos objetivos aos quais se destina e da população a ser atingida, respeitando-se a disponibilidade de alimentos regionais e os hábitos alimentares, pois assim ela pode se tornar um guia prático de orientação nutricional.

\section{A GRADECIMENTOS}

Mariana Nogueira Ferreira bolsista PIBIC-CNPq, e as alunas de Graduação do Curso de Nutrição, Faculdade de Saúde Pública, USP, Camila Gonçalves Guimarães e Roberta de Lima Reis Coutinho.

\section{REFERÊ NCIAS}

1. Monteiro CA, et al. Evolução da desnutrição infantil. In: Monteiro CA, organizador. Velhos e novos males da saúde no Brasil. São Paulo: Hucitec; 1995. p.93-114.

2. Bartrina JA. Nutrición en la edad evolutiva. In: Serra Majem L, Bartrina JA, Verdú JM. Nutrición y salud pública: métodos, bases científicas y aplicaciones. Madrid: Masson; 1995. p.90-106.

3. Alviña M. Alimentación del preescolar y escolar menor. In: Ruz OM, et al. editores. Nutrición y salud. Santiago: Universidad de Chile; 1996. p.201-11.

4. Ctenas MLB, Vitolo MR. Crescendo com saúde: o guia de crescimento da criança. São Paulo: C2 Editora e Consultoria em Nutrição; 1999.

5. United States Department of Agriculture. Tips for using the food guide pyramid for young children 2 to 6 years old [serial online] 1999. [cited 2000 jun 26]. Available from: URL: http://www.usda.gov/ cnpp/KidsPyra/PyrBook.pdf

6. Philippi ST, Colucci ACA, Cruz ATR, Ferreira MN, Coutinho RLR. Alimentação saudável na infância e na adolescência. In: Curso de atualização em alimentação e nutrição para professores da rede pública de ensino, 2000; Piracibaca. Piracicaba: Escola Superior de Agricultura Luiz de Queiroz; 2000. p.46-60.

7. Saúde Brasil. Nutrição pré-escolar \& escolar [vídeo cassete]. São Paulo: Aguilla; 1999. 28 min.

8. Philippi ST, Ribeiro LC, Latterza AR, Cruz ATR. Pirâmide alimentar adaptada: guia para escolha dos alimentos. Rev Nutr 1999a; 12(1):65-80.

9. Peña M, Molina V. Guias alimentarias y promoción de la salud en América Latina. Washington (DC): Organización Panamericana de la Salud; 1998.

10. Philippi ST, Fisberg RM, Cruz ATR, Colucci ACA. Pirâmide alimentar infantil. In: Anais do $5^{\circ}$ Congresso Nacional da Sociedade Brasileira de Alimentação e Nutrição, 1999; São Paulo. São Paulo: Sociedade Brasileira de Alimentação e Nutrição;1999b. p.186.

11. Philippi ST, Fisberg RM, Latterza AR, Cruz ATR, Colucci ACA, Fisberg M. Pirâmide alimentar infantil. In: Anais da $1^{\text {a }}$ Semana Acadêmica de Ciência e Cultura da Faculdade de Saúde Pública - USP, 1999; São Paulo. São Paulo: Faculdade de Saúde Pública - USP; 1999c. p.57. 
12. Philippi ST. Guia alimentar para o ano 2000. In: De Angelis RC. Fome oculta: impacto para a população do Brasil. São Paulo: Atheneu; 1999d. p.160-76.

13. Philippi ST, Fisberg RM, Latterza AR, Cruz ATR, Colucci ACA, Fisberg M. Pirâmide alimentar infantil. In: Anais da $36^{a}$ Reunião da Sociedade Latino Americana de Investigação Pediátrica, $12^{a}$ Reunião da Sociedade Latino Americana de Endocrinologia Pediátrica, $2^{a}$ Reunião da Associação Latino Americana de Nefrologia Pediátrica, 1998; São Pedro. São Pedro: SLAIP; 1998. p.64.

14. National Research Council (USA). Recommended dietary allowances. 10th ed. Washington (DC): National Academy Press; 1989.

15. Philippi ST, Szarfarc SC, Latterza AR. Virtual Nutri [programa de computador]. Versão 1.0 for Windows. São Paulo: Departamento de Nutrição da Faculdade de Saúde Pública/USP; 1996.

16. Monsen ER, Balintfy JL. Calculating dietary iron bioavailability refinement and computerization. J Am Diet Assoc 1982; 80(4): 307-11.
17. Colucci ACA, Fisberg RM, Philippi ST. Avaliação dos níveis de ferro total e biodisponível na pirâmide alimentar. In: Anais da $51^{\circ}$ Reunião Anual da Sociedade Brasileira para o Progresso da Ciência - SBPC; 1999; Porto Alegre. Porto Alegre: Sociedade Brasileira para o Progresso da Ciência; 1999.

18. Peña M. Guias de Alimentación en América Latina. In: $1^{\circ}$ Workshop Instituto Danone. Alimentação equilibrada para a população brasileira, 1998, Florianópolis. Florianópolis: Instituto Danone; 1998. p.31-43.

19. Yañez ER, Olivares SC, Torres LI, Guevara MN. Validación de las guías y la pirámide alimentaria en escolares de $5^{\circ}$ a $8^{\circ}$ básico. Rev Chil Nutr 2000; 27(3): 358-67.

20. Monte CMG, Giugliani ERJ, Carvalho MFCC, Philippi ST, Albuquerque ZPA. Guia alimentar para crianças menores de dois anos. Brasília: Ministério da Saúde; 2002.

Recebido para publicação em 18 de dezembro de 2000 e aceito em 10 de maio de 2002. 


\section{ANEXOS}

\section{ANEXO 1}

GRUPO DO ARROZ / PÃO / MASSA / BATATA / MANDIOCA. VALORES EXPRESSOS EM GRAMAS E MEDIDAS CASEIRAS.

1 Porção $=75$ kcal.

\begin{tabular}{|c|c|c|}
\hline Alimentos & Peso (g) & Medida Caseira \\
\hline Aipim cozido / Macaxeira / Mandioca & 48,0 & $11 / 2$ colher de sopa \\
\hline Amido de milho - maisena & 20,0 & 1 colher de sopa \\
\hline Arroz branco cozido & 62,0 & 2 colheres de sopa \\
\hline Arroz integral cozido & 70,0 & 2 colheres de sopa \\
\hline Aveia (em flocos) & 18,0 & $1 \frac{1}{2}$ colher de sopa \\
\hline Batata cozida & 88,0 & 1 unidade \\
\hline Batata doce cozida & 75,0 & 1 colher de servir \\
\hline Biscoito de leite & 16,0 & 3 unidades \\
\hline Biscoito recheado chocolate / doce de leite / morango & 17,0 & 1 unidade \\
\hline Biscoito tipo cream cracker & 16,0 & 3 unidades \\
\hline Biscoito tipo "maisena" & 20,0 & 4 unidades \\
\hline Biscoito tipo "maria" & 17,0 & 4 unidades \\
\hline Biscoito tipo wafer chocolate / morango / baunilha & 15,0 & 1 unidade \\
\hline Bolo de chocolate & 15,0 & $1 / 2$ fatia \\
\hline Cará amassado / inhame & 63,0 & 2 colheres de sopa \\
\hline Cereal matinal & 21,0 & 1/2 xícara de chá \\
\hline Creme de arroz & 23,0 & $11 / 2$ colher de sopa \\
\hline Farinha de mandioca torrada & 24,0 & $11 / 2$ colher de sopa \\
\hline Farinha láctea & 19,0 & $21 / 2$ colheres de sopa \\
\hline Fubá & 22,0 & 1 colher de sopa \\
\hline Macarrão cozido & 53,0 & 2 colheres de sopa \\
\hline Mandioquinha cozida / Batata Baroa / Salsa & 70,0 & $1 / 2$ escumadeira \\
\hline Pão de fôrma tradicional & 21,0 & 1 fatia \\
\hline Pão de queijo & 20,0 & $1 / 2$ unidade \\
\hline Pão francês & 25,0 & $1 / 2$ unidade \\
\hline Pão tipo "bisnaguinha" & 40,0 & 2 unidades \\
\hline Pipoca com sal & 11,0 & 1 xícara de chá \\
\hline Polenta sem molho / Angu & 100,0 & 1 fatia \\
\hline Purê de batata & 67,0 & 1 colher de servir \\
\hline Torrada de pão francês & 16,0 & 3 fatias \\
\hline
\end{tabular}




\section{ANEXO 2}

GRUPO DAS VERDURAS E LEGUMES. VALORES EXPRESSOS EM GRAMAS E MEDIDAS CASEIRAS.

1 Porção = 8 kcal.

\begin{tabular}{|c|c|c|}
\hline Alimentos & Peso (g) & Medida Caseira \\
\hline Abóbora cozida / Jerimum & 26,0 & 1 colher de sobremesa \\
\hline Abobrinha cozida & 40,0 & $11 / 2$ colher de sopa \\
\hline Acelga cozida & 51,0 & $11 / 2$ colher de sopa \\
\hline Alface & 64,0 & 8 folhas \\
\hline Almeirão & 36,0 & 3 folhas \\
\hline Berinjela cozida & 30,0 & 1 colher de sopa \\
\hline Beterraba cozida & 15,0 & $1 / 2$ colher de servir \\
\hline Beterraba crua ralada & 21,0 & 1 colher de sopa \\
\hline Brócolis cozido & 27,0 & 2 colheres de sopa \\
\hline Cenoura cozida (fatias) & 20,0 & 4 fatias \\
\hline Cenoura crua (picada) & 20,0 & 1 colher de sopa \\
\hline Chuchu cozido & 28,0 & $11 / 2$ colher de sopa \\
\hline Couve-flor cozida & 34,0 & $11 / 2$ ramo \\
\hline Couve manteiga cozida & 21,0 & 1 colher de sopa \\
\hline Ervilha fresca & 10,0 & $3 / 4$ colher de sopa \\
\hline Ervilha torta / Vagem & 5,0 & 1 unidade \\
\hline Escarola & 45,0 & 8 folhas \\
\hline Espinafre cozido & 30,0 & 1 colher de sopa \\
\hline Jiló cozido & 20,0 & 1 colher de sopa \\
\hline Mostarda & 30,0 & 3 folhas \\
\hline Pepino japonês & 65,0 & $1 / 2$ unidade \\
\hline Pepino picado & 58,0 & 2 1/2 colheres de sopa \\
\hline Pimentão cru fatiado (vermelho, verde) & 35,0 & 4 fatias \\
\hline Quiabo cozido & 26,0 & 1 colher de sopa \\
\hline Rabanete & 51,0 & 2 unidades \\
\hline Repolho branco/roxo cru (picado) & 36,0 & 3 colheres de sopa \\
\hline Repolho cozido & 28,0 & $21 / 2$ colheres de sopa \\
\hline Tomate caqui & 38,0 & $1 \frac{1}{2}$ fatia \\
\hline Tomate comum & 40,0 & 2 fatias \\
\hline Vagem cozida & 22,0 & 1 colher de sopa \\
\hline
\end{tabular}




\section{ANEXO 3}

GRUPO DAS FRUTAS. VALORES EXPRESSOS EM GRAMAS E MEDIDAS CASEIRAS.

1 Porção = 35 kcal.

\begin{tabular}{|c|c|c|}
\hline Alimentos & Peso $(\mathrm{g})$ & Medida Caseira \\
\hline Abacate & 24,0 & $3 / 4$ colher de sopa \\
\hline Abacaxi & 65,0 & $1 / 2$ fatia \\
\hline Acerola & 128,0 & 1 xícara de chá \\
\hline Ameixa preta & 15,0 & $11 / 2$ unidade \\
\hline Ameixa vermelha & 70,0 & 2 unidades \\
\hline Banana nanica & 43,0 & $1 / 2$ unidade \\
\hline Caju & 40,0 & $11 / 2$ unidade \\
\hline Caqui & 50,0 & $1 / 2$ unidade \\
\hline Carambola & 110,0 & 1 unidade \\
\hline Fruta do conde / Ata / Pinha & 35,0 & $1 / 4$ unidade \\
\hline Goiaba & 50,0 & $1 / 4$ unidade \\
\hline Jabuticaba & 68,0 & 17 unidades \\
\hline Jaca & 66,0 & 2 bagos \\
\hline Kiwi & 60,0 & $3 / 4$ unidade \\
\hline Laranja Bahia / Seleta & 80,0 & 4 gomos \\
\hline Laranja Pêra / Lima espremida para chupar & 75,0 & 1 unidade \\
\hline Limão & 126,0 & 2 unidades \\
\hline Maçã & 60,0 & $1 / 2$ unidade \\
\hline Mamão formosa & 110,0 & 1 fatia \\
\hline Mamão papaia & 93,0 & $\alpha$ unidade \\
\hline Manga & 55,0 & $1 / 2$ unidade \\
\hline Melancia & 115,0 & 1 fatia \\
\hline Melão & 108,0 & 1 fatia \\
\hline Morango & 115,0 & 9 unidades \\
\hline Pêra & 66,0 & $1 / 2$ unidade \\
\hline Pêssego & 85,0 & $3 / 4$ unidade \\
\hline Suco de abacaxi & 80,0 & $1 / 2$ copo de requeijão \\
\hline Suco de laranja & 85,0 & $1 / 2$ copo de requeijão \\
\hline Suco de melão & 85,0 & $1 / 2$ copo de requeijão \\
\hline Tamarindo & 12,0 & 6 unidades \\
\hline Tangerina / Mexerica / Mimosa / Bergamota & 84,0 & 6 gomos \\
\hline Uva comum & 50,0 & 11 bagos \\
\hline Uva Itália & 50,0 & 4 bagos \\
\hline
\end{tabular}




\section{ANEXO 4}

GRUPO DOS FEIJÕES. VALORES EXPRESSOS EM GRAMAS E MEDIDAS CASEIRAS.

1 Porção = $20 \mathrm{kcal}$

\begin{tabular}{lcc}
\hline Alimentos & Peso $(\mathrm{g})$ & Medida Caseira \\
\hline Ervilha seca cozida & 24,0 & 1 colher de sopa \\
Feijão branco cozido & 16,0 & $1 / 2$ colher de sopa \\
Feijão cozido (50\% grão / 50\% caldo) & 26,0 & 1 colher de sopa \\
Feijão cozido (só grãos) & 16,0 & $3 / 4$ colher de sopa \\
Grão de bico cozido & 12,0 & $3 / 4$ colher de sopa sopa \\
Lentilha cozida & 16,0 & $3 / 4$ colher de sopa \\
Soja cozida & 18,0 & \\
\hline
\end{tabular}

ANEXO 5

GRUPO DO LEITE, QUEIJO E IOGURTES. VALORES EXPRESSOS EM GRAMAS E MEDIDAS CASEIRAS.

1 Porção = 120 kcal.

\begin{tabular}{|c|c|c|}
\hline Alimentos & Peso (g) & Medida Caseira \\
\hline Bebida láctea & 150,0 & 1 pote \\
\hline logurte de frutas & 140,0 & 1 pote \\
\hline logurte polpa de frutas & 120,0 & 1 pote \\
\hline logurte polpa de frutas com geléia & 130,0 & 1 pote \\
\hline Leite em pó integral & 30,0 & 2 colheres de sopa \\
\hline Leite esterilizado (Longa Vida) & 182,0 & 1 xícara de chá \\
\hline Leite fermentado & 160,0 & 2 potes \\
\hline Leite tipo B & 182,0 & 1 xícara de chá \\
\hline Leite tipo C & 182,0 & 1 xícara de chá \\
\hline Queijinho pasteurizado fundido & 35,0 & 2 unidades \\
\hline Queijo petit suisse & 90,0 & 2 potes \\
\hline Queijo minas & 50,0 & $11 / 2$ fatia \\
\hline Queijo mussarela & 45,0 & 3 fatias \\
\hline Queijo parmesão & 30,0 & 3 colheres de sopa \\
\hline Queijo pasteurizado & 40,0 & 2 fatias \\
\hline Queijo prato & 40,0 & 2 fatias \\
\hline Queijo provolone & 35,0 & 1 fatia \\
\hline Requeijão cremoso & 45,0 & $11 / 2$ colher de sopa \\
\hline Sobremesa láctea tipo "pudim de leite" & 90,0 & 1 pote \\
\hline Vitamina de leite com frutas & 171,0 & 1 copo de requeijão \\
\hline
\end{tabular}




\section{ANEXO 6}

GRUPO DE CARNE BOVINA, SUÍNA, PEIXES, FRANGO E OVOS. VALORES EXPRESSOS EM GRAMAS E MEDIDAS CASEIRAS. 1 Porção $=65 \mathrm{kcal}$

\begin{tabular}{lll}
\hline Alimentos & Peso $(\mathrm{g})$ & Medida Caseira \\
\hline Bife enrolado & 36,0 & $\alpha$ unidade \\
Bife bovino grelhado & 21,0 & $\alpha$ unidade \\
Bife de fígado bovino & 34,0 & $1 / 4$ unidade \\
Carne bovina assada / cozida & 26,0 & $\alpha$ fatia \\
Carne bovina moída refogada & 30,0 & 2 colheres de sopa \\
Coração de frango & 40,0 & 2 unidades \\
Espetinho de carne & 31,0 & $3 / 4$ unidade \\
Fígado de frango & 45,0 & 3 unidades \\
Filé de frango à milanesa & 26,0 & $\alpha$ unidade \\
Filé de frango grelhado & 33,0 & $\alpha$ unidade \\
Frango assado inteiro & 33,0 & $\alpha$ peito ou $\alpha$ coxa ou $\alpha$ sobrecoxa \\
Hambúrguer & 45,0 & $1 / 2$ unidade \\
Lombo de porco assado & 26,0 & $\alpha$ fatia \\
Manjuba frita & 35,0 & 3 unidades \\
Merluza/ Pescada cozida & 66,0 & 1 filé \\
Moela & 27,0 & 1 unidade \\
Nugget de frango & 24,0 & 1 1/2 unidade \\
Omelete simples & 25,0 & $\alpha$ unidade \\
Ovo cozido & 50,0 & 1 unidade \\
Ovo frito & 25,0 & $1 / 2$ unidade \\
Presunto & 40,0 & 2 fatias \\
Sardinha frita & 51,0 & $1 / 2$ unidade \\
Sobrecoxa de frango cozida com molho & 37,0 & $1 / 4$ unidade \\
\hline
\end{tabular}

\section{ANEXO 7}

GRUPO DOS ÓLEOS E GORDURAS. VALORES EXPRESSOS EM GRAMAS E MEDIDAS CASEIRAS.

1 Porção $=37 \mathrm{kcal}$

\begin{tabular}{lcl}
\hline Alimentos & Peso $(\mathrm{g})$ & Medida Caseira \\
\hline Azeite de oliva & 4,0 & 2 colheres de chá \\
Creme vegetal & 7,0 & 1 colher de chá \\
Manteiga & 5,0 & 1 colher de chá \\
Margarina vegetal & 5,0 & 1 colher de chá \\
Óleo misto (soja e oliva) & 4,0 & 2 colheres de chá \\
Óleo vegetal & 4,0 & 2 colheres de chá \\
\hline
\end{tabular}




\section{ANEXO 8}

GRUPO DOS AÇÚCARES E DOCES. VALORES EXPRESSOS EM GRAMAS E MEDIDAS CASEIRAS.

1 Porção = $55 \mathrm{kcal}$

\begin{tabular}{lll}
\hline Alimentos & Peso $(\mathrm{g})$ & Medida Caseira \\
\hline Achocolatado em pó & 17,0 & 1 colher de sopa \\
Açúcar cristal & 15,0 & 3 colheres de chá \\
Açúcar mascavo & 14,0 & 1 colher de sopa \\
Açúcar refinado & 14,0 & 1 colher de sobremesa \\
Doce de leite cremoso & 20,0 & 1 colher de sopa \\
Geléia & 23,0 & 1 1/2 colher de sobremesa \\
Glucose de milho & 20,0 & 1 colher de sopa \\
Goiabada & 23,0 & $1 / 4$ fatia \\
\hline
\end{tabular}

